\title{
Racial Disparities in Arrests: A Race Specific Model Explaining Arrest Rates Across Black and White Young Adults
}

\author{
Cydney Schleiden ${ }^{1} \cdot$ Kristy L. Soloski $^{1} \cdot$ Kaitlyn Milstead $^{1} \cdot$ Abby Rhynehart $^{2}$
}

Published online: 3 May 2019

(c) Springer Science+Business Media, LLC, part of Springer Nature 2019

\begin{abstract}
Three theories attempt to explain the racial disparities in arrest between White and Black Americans: Differential Involvement Hypothesis, Differential Selection and Processing Hypothesis, and Social Disorganization Theory. We tested these hypotheses simultaneously in a multiple-group longitudinal panel model with the ADD Health dataset (Black $n=2459$, White $n=7403$ ). After controlling for contextual and behavioral factors, we still found Black young adults were arrested seven times more often than their White counterparts. To maintain cultural competence, it is imperative for clinicians to be aware of these disparities when working with families of different races in order to adjust treatment accordingly, but advocacy for greater systemic change may be more important for some communities than therapy alone.
\end{abstract}

Keywords Racial disparities $\cdot$ Arrest $\cdot$ Violence $\cdot$ Neighborhood disadvantage $\cdot$ Parent-child bond

A racial/ethnic disparity in arrest rates between Black and White persons is well documented. Black individuals are disproportionately arrested and imprisoned compared to that of the White population. As of 2013, Black juveniles were arrested at twice the rate of White juveniles (Puzzanchera \& Hockenberry, 2015). Although overall juvenile arrests have decreased, arrest rates of Black youth are decreasing at a significantly slower pace than White youth. Research suggests a similar disparity among the adult population. By the age of 18 , Black males are at a $30 \%$ risk of arrest compared

We would like to dedicate this research to the incarcerated minority adolescents who inspired us to tell their story in hopes to provide them with equal opportunity and create awareness for others to advocate for the betterment of their future.

Cydney Schleiden

Cydney.schleiden@ttu.edu

Kristy L. Soloski

Kristy.soloski@ttu.edu

Kaitlyn Milstead

Kaitlyn.milstead@ttu.edu

Abby Rhynehart

Abby.rhynehart@ttu.edu

1 Marriage and Family Therapy, Texas Tech University, Lubbock, TX, USA

2 Texas Tech University, Lubbock, TX, USA to $22 \%$ for White males, and by the age of 23 , Black males are at a $49 \%$ risk of arrest, whereas White males are at a $38 \%$ risk of arrest (Barnes, Jorgenson, Beaver, Boutwell, \& Wright, 2014). The purpose of this study is to examine the racial disparities in arrests between Black and White populations and attempt to explain these disparities by examining prominent predictors (i.e., neighborhood disadvantage, exposure to violence, and parent-child bond). Including each of these predictors allows us to test three theories that attempt to explain this disparity: Social Disorganization Theory (Sampson \& Groves, 1989), Differential Involvement Hypothesis, and Differential Selection and Processing Hypothesis (Piquero, 2008).

The theories/hypotheses that will be discussed in this paper seek to explain arrest disparities with focuses on different factors: The Social Disorganization Theory, the Differential Involvement Hypothesis, and the Differential Selection and Processing Hypothesis (Sampson \& Groves, 1989; Piquero, 2008). Although the documented racial disparities in arrests are clear, the cause of these disparities remains unclear, and support has been found for each of the competing theories/hypotheses complicating our understanding of what is the cause (e.g., Gase et al., 2016; Sampson \& Groves, 1989; Piquero, 2008). Broadly, the factors each theory examines to account for disparities in arrests can be labeled as either "warranted" or "unwarranted" (Gase et al., 2016). "Warranted factors", include behaviors related 
to criminal involvement that are legally relevant and arrest is justifiable (Gase et al., 2016). "Unwarranted factors" are factors that lead to arrest and are not explained by legally relevant variables, for example, racial bias in the justice system (Spohn, 2000). The Social Disorganization Theory and the Differential Involvement Hypothesis hinge on "warranted factors", whereas the Differential Selection and Processing Hypothesis address "unwarranted factors". Support for each theory would have very different implications, particularly affecting allocation of responsibility for change. For example, the Differential Involvement Hypothesis would place responsibility on the community in creating behavior change to reduce the arrest rates, whereas the Differential Selection and Processing Hypothesis would stress the need for institutional change to eliminate biased practices and allocate resources for communities in need. The loss and impact bore by the individual and community because of arrest rates is high, and thus it is imperative to collectively examine each of these theories. To affect change, individuals advocating for marginalized youth need an understanding of the factors affecting the population, regarding arrest disparities.

The arrest disparity is problematic for a number of reasons. Once individuals become involved with the criminal justice system, stigma can negatively impact their lives. For example, the individual may be given labels such as "criminal" or "troublesome" (Pratt, Barnes, Cullen, \& Turanovic, 2016). These labels can lead to difficulties in an individual's life including: difficulty obtaining an education, difficulty finding employment, recidivism rates, marital status, and socioeconomic status (Pratt et al., 2016). Not only are there individual costs, but there are also consequences of arrest that also affect families and communities (Kamalu, CoulsonClark, \& Kamalu, 2010). These outcomes include: relational conflicts, increased community rates of unemployment, inability to vote, contraction of infectious diseases, public benefits, and welfare dependence (Hamil-Luker, 2008).

Understanding the cause of arrest disparities is complicated when warranted and unwarranted factors are not considered together. For example, consider that the reasons for arrests between Black and White individuals differ, and seemingly point to differences in behavior. White individuals are more likely to get arrested for sexual assault, property crimes, and public order, whereas Black individuals are more likely to be arrested for murder, robbery and drug offenses (Carson \& Golinelli, 2013). However, when you look at behavior outside of the context of differences in arrest charges, although Black individuals are more likely to be arrested for drug-related offenses, they are less likely than White individuals to use drugs (Mitchell \& Caudy, 2013). Warranted and unwarranted factors need to be considered together in order to acknowledge systemic biases that may be barriers to underserved populations. The Social Disorganization Theory, Differential Involvement Hypothesis, and
Differential Selection and Processing Hypothesis each have a different view of what "warranted" and "unwarranted" factors account for the observed arrest disparities. The combination of factors have not previously been collectively examined in one study, making it difficult to understand the competing results of these theories/hypotheses.

\section{Arrest Disparities}

\section{Unwarranted Factors}

An important factor when considering racial disparities in arrests is the environmental and social contexts surrounding each population. The Social Disorganization Theory suggests that social context and environments can look differently among Black and White individuals, and these differences could contribute to the disproportionate arrest rates rather than inherent racial differences (Gase et al., 2016). Socioeconomic disadvantage amongst communities, in part created through residential segregation, disrupts family relationships, creates social isolation and instability within the community, and limits access to resources, which lead to "deviant behaviors" (Gase et al., 2016, p. 297). Socioeconomic disadvantage, an unwarranted factor, creates an environment affecting social differences, and then crime rates in the area affect the police presence.

Although some evidence points to different rates of crime potentially stemming from societal experiences, other evidence points to a difference in the policies and practices of the judicial system regarding Black and White Americans. The Differential Selection and Processing Hypothesis suggests protocols and processes put into place by justice systems lead to more minorities being arrested (Gase et al., 2016). Policies and procedures of the justice system not only affect arrest rates, but also affect the perception of differences in behavior, and presumed character, between Black and White Americans. Studies have shown that there is an evident amount of heavier "police emphasis on drug control" in a minority neighborhood, leading to more arrests among minorities (Mitchell \& Caudy, 2013, p. 309). One study found that probation officers were more likely to attribute the delinquent behaviors of Black adolescents to negative personality traits, and attribute White adolescent delinquency behaviors to causality of social environment (Bechtold, Monahan, Wakefield, \& Cauffman, 2015). Another study found that those who have been previously arrested are more likely to be arrested again once they return to disadvantaged neighborhoods (Kubrin \& Stewart, 2006). It has also been reported that police officers attribute the pigment of an individual's skin to the likelihood of engagement in criminal behavior, which supports the suggestion that this perceptional difference could explain the racial 
disparities in arrests that we are seeing today (Graham \& Lowery, 2004). Unwarranted factors accounting for arrest rate differences is supported when differences in contextual factors and the relation between contextual factors and arrest rates are found.

\section{Warranted Factors}

Some believe that the racial disparity in arrests is solely due to the differences in behaviors among Black and White Americans. The Differential Involvement Hypothesis states that warranted factors, meaning differences in criminal behaviors, account for why these populations are being arrested at a higher rate. This theory states that in the juvenile and criminal justice systems there is a larger number of minorities because minorities are committing more crimes over a longer period of time and are engaging in more criminal behaviors (Gase et al., 2016). Studies comparing self-reports on criminal activity have found that Black individuals, compared to White individuals, commit more serious crimes, which are more likely to be reported to police leading to arrests (Piquero, 2008), which seemingly supports this hypothesis. Warranted factors accounting for arrest disparities is supported when behavioral differences fully account for the differences found.

Although the Differential Involvement Hypothesis believes that minorities do in fact commit more crimes, studies have found that there is more to the overrepresentation of minorities in juvenile and justice systems than criminal behavioral differences. Longitudinal studies found after controlling for differences in offending, racial differences in police contact remained significant (Gase et al., 2016). Additionally, studies controlling for factors such as criminal behavior, substance use, and mental health issues, found minority youth continued to be more likely involved in the justice system (Gase et al., 2016). Without considering factors from each theory within the same analysis, the picture of what accounts for the disparities can be very different.
The social implications for any given theory could be very high, ranging from affecting stigma to affecting allocation of resources to the community. Thus, it is crucial that research examining this disparity consider simultaneously consider multiple theories and include a variety of individual and contextual factors within the analyses.

\section{The Current Study}

The purpose of this study is to explain the racial disparities in arrests (Note. We refer to "arrests" as "outcome" throughout this study) between the Black and White populations, by incorporating variables that allow us to simultaneously test the Social Disorganization Theory, the Differential Involvement Hypothesis, and the Differential Selection and Processing Hypothesis. Variables included can be categorized as contextual factors (i.e., neighborhood disadvantage, exposure to violence, parent-child bond, and interactions with neighborhood disadvantage), behaviors (i.e., alcohol use, drug use, and delinquency), and arrest outcomes. The inclusion of contextual and behavioral factors allows us to test one theory while also controlling for factors that support another. For example, we will be able to test the Social Disorganization Theory's explanation for arrest disparities, while controlling for factors supporting the Differential Involvement Hypothesis and the Differential Selection and Processing Hypothesis. There is a significant amount of literature regarding racial disparities it arrests, yet studies suggest different reasons for the disparity Gase et al., 2016; Sampson \& Groves, 1989; Piquero, 2008). We are filling the gap in literature by addressing three primary theories/ hypotheses that give explanation for racial disparities in arrest, by testing them simultaneously for clarity regarding this issue.

We will be examining the following research questions (see Fig. 1): (1) Is there a direct association between contextual factors in adolescence and both behavior and arrest outcomes in emerging adulthood and arrest outcomes in young adulthood?
Fig. 1 This figure does not depict the included demographics

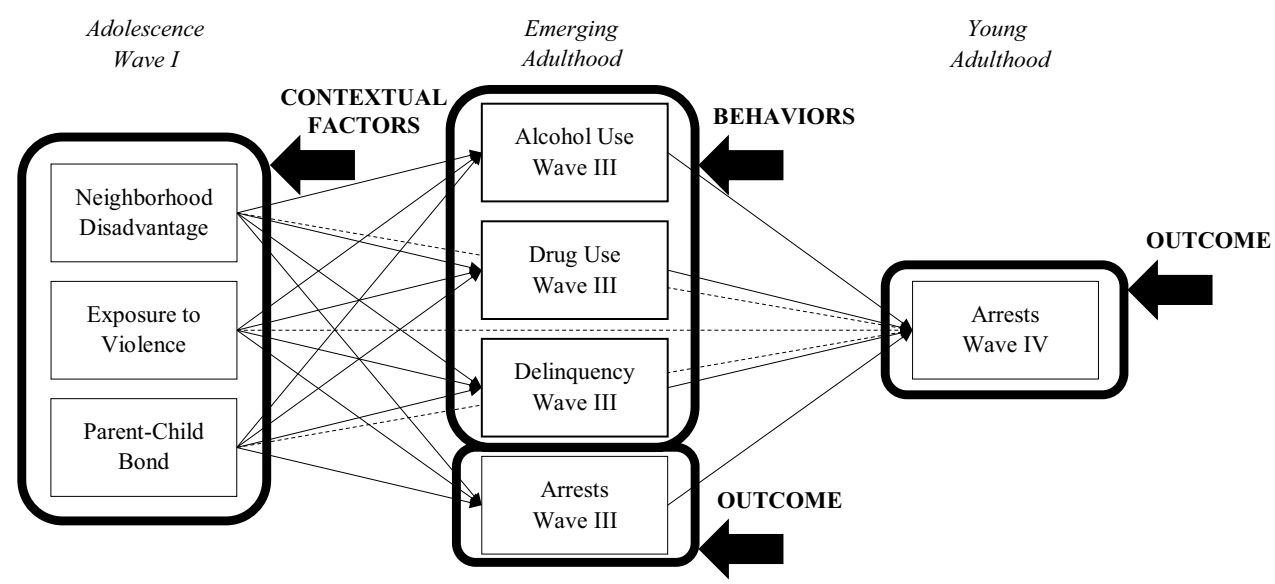


(2) Is there a direct association between behavior and arrest outcomes in emerging adulthood and arrest outcomes in young adulthood? (3) Is there a mean difference in contextual factors, behavior, and arrest outcomes for those who identify as Black compared to those who identify as White? (4) Is there a difference in the strength of the relation between contextual factors, behavior, and outcome between those who identify as Black or for those who identify as White? A different combined pattern of results across the research questions would support each theory/hypothesis, and are our hypothesized results for each theory. We will review that hypothesized pattern of results for each theory/hypothesis below.

\section{Social Disorganization Theory}

Social disorganization theory will be supported if there is on average more neighborhood disadvantage, more exposure to violence, and less parent-child bond for those who identify as Black compared to those who identify as White. The contextual factors will be significantly related to both behavior and outcome. However, there will be no mean differences between the races in behavior or outcome after controlling for contextual factors, nor will there be significant difference between races in the relations between contextual factors, behavior, and outcome.

\section{Differential Involvement Hypothesis}

Differential involvement hypothesis will be supported if those who identify as Black have on average higher behavior and outcome rates than those who identify as after controlling for contextual factors. There will be no differences in how contextual factors, behavior, and outcome are related between those who identify as Black and those who identify as White.

\section{Differential Selection and Processing Hypothesis}

Differential selection and processing hypothesis will be supported if there is a mean difference outcome, but not behavior after controlling for contextual factors. Contextual factors will more strongly be related to both behavior and outcome for those who identify as Black than those who identify as White. Behavior and outcome in emerging adulthood will be stronger predictors of behavior and outcome in young adulthood for those who identify as Black than those who identify as White.

\section{Methods}

\section{Procedures and Participants}

For this study we used the National Longitudinal Study of Adolescent to Adult (ADD) Health data set (Harris et al.,
2009). This school-based study was a sample of 80 high schools, as well as 52 middle schools, in the United States. A clustered sampling design was used to collect the data and schools were considered eligible if they had an 11th grade class and had at least 30 students enrolled. Data was collected from the adolescent, parents, siblings, friends, and school administrators through multiple sources. The sample included diverse adolescents and looked at variables such as poverty, crime, unemployment, and additional contextual information. This longitudinal data set currently consists of four waves of data, starting with the first in-home wave (Wave I) which included 20,745 adolescents in 7 th to 12 th grade. The first wave of data was collected from September 1994 through December 1995. The study followed-up with these adolescents by conducting an additional three in-home interviews in 1996, 2001-2002, and 2007-2008 respectively. A fifth wave of data collection began in 2016 , and will continue through 2018 , where the sample age will be 32 to 42 years old.

For the current study, variables of interest came from Wave I, Wave III, and Wave IV, where we examined differences between Black/African American participants $(n=2459)$ and White/Caucasian participants $(n=7403)$. These waves were selected so that each time point represented a different developmental period: adolescence, emerging adulthood, and young adulthood. The response rate at Wave I was 79\%, at Wave III was $77.4 \%$, and at Wave IV is was $80.3 \%$. The average age of participants in this study was 15 at Wave I for the Black group and the White group. In the Black group there were $58.6 \%$ female participants and $41.4 \%$ male participants, while in the White group there were $53.7 \%$ female participants and $46.3 \%$ male participants. The average annual income in the Black group was $\$ 28,900$ and in the White group it was $\$ 49,900$.

\section{Measures}

Descriptive information, including means, standard deviations, and the range for each construct can be found in Table 1 for ease of viewing.

\section{Neighborhood Disadvantage}

Add Health corresponded the 1990 Census of Population and Housing data to region of residence for the participants to provide contextual information about the community participants were being raised in. Guided by the social disorganization theory, Slutske, Deutsch, and Piasecki (2016) created a neighborhood disadvantage construct by combining census tract data from 10 indicators of neighborhood quality to create a mean proportion of disadvantage. Indicators of the neighborhood quality factor included: (1) proportion of single-parent households with children under 18, (2) average 
Table 1 Descriptives table by racial groups: Black participants $(n=2459)$ and White participants $(n=7403)$

\begin{tabular}{|c|c|c|c|c|}
\hline & \multicolumn{2}{|l|}{ Black } & \multicolumn{2}{|l|}{ White } \\
\hline & $M(S D)$ or $\%$ & Range & $M(S D)$ or $\%$ & Range \\
\hline Neighborhood disadvantage & $.21(.05)$ & $.09-.34$ & $.15(.04)$ & $.07-.30$ \\
\hline Exposure to violence & $.99(1.22)$ & $0-6$ & $.61(1.05)$ & $0-6$ \\
\hline Parent-child bond & $4.40(.64)$ & $1.20-5.00$ & $4.35(.62)$ & $1-5$ \\
\hline Alcohol use WIII & $1.44(1.73)$ & $0-6$ & $2.44(1.74)$ & $0-6$ \\
\hline Drug use WIII & $.65(.98)$ & $0-8$ & $1.5(2.03)$ & $0-9$ \\
\hline Delinquency WIII & $.08(.22)$ & $0-2$ & $.07(.17)$ & $0-3$ \\
\hline Arrests WIII & $.36(1.82)$ & $0-43$ & $.28(1.26)$ & $0-35$ \\
\hline Arrests WIV & $1.06(4.35)$ & $0-105$ & $.61(2.58)$ & $0-62$ \\
\hline Age & $15.65(1.87)$ & $11-21$ & $15.39(1.81)$ & $11-21$ \\
\hline Biological sex & & $0-1$ & & $0-1$ \\
\hline Male & 41.36 & & 46.28 & \\
\hline Female & 58.64 & & 53.72 & \\
\hline Income & $28.90(29.66)$ & $0-503$ & $49.90(46.43)$ & 0-999 \\
\hline
\end{tabular}

of the proportion of persons and (3) families with income in 1989 below poverty level, (4) proportion Black, (5) proportion Hispanic origin, (6) average proportion aged $25+$ with no high school diploma or equivalency and (7) proportion with no college degree, (8) average of the proportion of housing units lacking complete kitchen and (9) plumbing facilities, and (10) the unemployment rate. Factor analyses identified acceptable model fit associated with this construct (Slutske et al., 2016), and internal reliability was good for both racial groups (Black $\alpha=.74$, White $\alpha=.78$ ).

\section{Exposure to Violence}

An exposure to violence in adolescence construct was created using six-items from Wave I. Participants were asked the frequency of the following events: "You saw someone shoot or stab another person", "Someone pulled a knife or gun on you", "Someone shot you", "Someone cut or stabbed you", "You got into a physical fight", "You were jumped". These questions were recoded so that $0=$ this has never happened, and 1=yes, this has happened once or more than once. The answers were summed and provided a numerical value of how many violent acts the participants had been exposed to in the past 12 months.

\section{Parent-Child Bond}

The parent-child bond construct was created using tenitems from the Wave I in-home survey (Crosnoe \& Elder, 2004). Five items that went into this measure were regarding mother-child bond and the same items were repeated to ask about father-child bond, for a total of ten parent-child bond questions. For example, on a five-point scale from $1=$ not at all to $5=$ very much, participants indicated how close they felt to their mother, and how much they felt their mother cared about them. On a five-point scale from $1=$ strongly agree to $5=$ strongly disagree, participants identified how much they agreed with the following statements, "Most of the time, your mother is warm and loving toward you", "You are satisfied with the way your mother and you communicate with each other", "Overall, you are satisfied with your relationship with your mother". Items were averaged to create a parent-child bond construct. Internal reliability was good for the measure (Black $\alpha=.87$, White $\alpha=.88$ ).

\section{Alcohol Use and Drug Use}

Substance during emerging adulthood and young adulthood was constructed using items from Wave III of the in-home survey. Frequency of alcohol use was assessed through the item, "During the past 12 months, on how many days did you drink alcohol?" with responses ranging on a sevenpoint scale: $0=$ never, $1=1$ or 2 days in the past 12 months, $2=$ one a month or less, $3=2$ or 3 days a month, $4=1$ or 2 days $a$ week, $5=3$ to 5 days a week, and $6=$ every day or almost every day.

Drug use since the previous wave of data collection in 1995 was assessed through nine-items in Wave III of the in-home survey. Participants were first assessed for their use of non-prescribed prescription drugs or use of prescription drugs in quantities or duration longer than prescribed: sedatives or downers (e.g., barbiturates, sleeping pills, Quaalude, or Seconal), tranquilizers (e.g., Librium, Valium, or Xanax), stimulants or uppers (e.g., amphetamines, prescription diet pills, Ritalin, Preludin, or speed), pain killers or opoids (e.g., Vicodin, OxyContin, Percocet, Tylenol with codeine). Other drug use was also assessed including steroid, marijuana, cocaine, crystal meth, other illicit drug use (e.g., LSD, PCP, ecstasy, heroin, mushrooms, or inhalants). Participants answered either $0=n o$ or $1=y e s$ to whether they used each 
of the drugs, responses were summed to create a number of drugs used variable.

\section{Delinquency}

The delinquency measure, was constructed using data from Wave III adapted from the work of Gase et al. (2016) examining delinquency at Wave I. At Wave III, delinquency in the past 12 months was assessed through 12-items asking how often the participant participated in behaviors including vandalism, theft, threat of violence, physical altercations, unruly behavior in public, financial fraud, and/or drug distribution. These items were answered on a four-point scale ranging from, $0=$ never, $1=1$ or 2 times, $2=3$ or 4 times, and $3=5$ or more times, and were averaged to create the frequency of delinquency construct (Black $\alpha=.76$, White $\alpha=.68$ ).

\section{Arrests}

The total number of lifetime arrests variable was constructed using data from Waves III and IV. In both waves, participants indicated how many times they were arrested both prior to and since reaching adulthood (i.e., age 18). The questions read, "How many times were you arrested before you were 18?" and "How many times have you been arrested since you were 18?" The responses to these questions were summed to create a total number of life time arrests variable in emerging adulthood and young adulthood. At Wave III, lifetime arrests ranged from 0 to 43 arrests (Black $M=.36$, $S D=1.82$; White $M=.28, S D=1.26$ ), and at Wave IV lifetime arrests ranged from 0 to 105 arrests (Black $M=1.06$, $S D=4.35$; White $M=.61, S D=2.58$ ).

\section{Demographics}

Information regarding demographics was taken from the Wave I in-home questionnaires. When identifying their race, participants could choose to identify as one, or more than one, of the following: White/Caucasian, Black/African American, Asian/Pacific Islander, American Indian/ Native American, or Other. For this study, participants who marked Black/African American were identified as the Black group ( $n=2459)$ and those who only marked White/Caucasian were identified as the White group $(n=7403)$. Age in years was calculated by using the participants' birthday and the date of the interview. Biological sex was coded with $0=$ male, and $1=$ female. Total family income was reported by parents in the parent in-home survey.

\section{Data Analysis}

The first stage of analyses examined descriptive statistics, implemented independent t-tests to test differences in delinquent behaviors and drugs used across racial groups, and examined bivariate correlations. We include all bivariate analyses in Table 2, these can be examined in comparison to results found in the final panel model. As these analyses are bivariate analyses only, confounds can affect our results, and third variables can account for any associations found here. The full panel model allows us to control for third variable confounds and allows us to control risk of familywise Type I error. To test the social disorganization theory, the differential involvement hypothesis, and the differential selection and processing hypothesis, we ran a longitudinal panel model with a grouping variable for race (i.e., Black and White) (see Fig. 1). This analysis allows us to examine and control for the effect of several variables from each theory/ hypothesis simultaneously without increasing Type I error risk, and allows us to examine whether the model is a sufficient fit to the data. Analyses were run using Mplus Version 8 (Muthén \& Muthén, 1998-2012) and sampling weights for analyses using data from Waves I, III, and IV were incorporated (Chantala, 2006). Age, gender, and income were control variables in the model with direct effects on the Wave III and IV variables. Race was examined as a grouping variable in the model, each pathway was iteratively constrained
Table 2 Correlation Matrix by racial groups: Black participants $(n=2459)$ and White participants $(n=7403)$

\begin{tabular}{lllllllll}
\hline & 1. & 2. & 3. & 4. & 5. & 6. & 7. & 8. \\
\hline 1. Neighborhood disadvantage & - & $-0.09^{*}$ & 0.06 & -0.05 & $-0.13^{*}$ & $-0.09^{*}$ & -0.04 & $-0.10^{*}$ \\
2. Exposure to violence & $0.09^{*}$ & - & $-0.08^{*}$ & $0.13^{*}$ & $0.14^{*}$ & $0.22^{*}$ & $0.18^{*}$ & $0.12^{*}$ \\
3. Parent-child bond & 0.03 & $-0.13^{*}$ & - & -0.02 & -0.05 & 0.01 & -0.01 & 0.04 \\
4. Alcohol use WIII & $-0.15^{*}$ & $0.04^{*}$ & -0.03 & - & $0.31^{*}$ & $0.18^{*}$ & 0.10 & 0.07 \\
5. Drug use WIII & 0.00 & $0.15^{*}$ & $-0.10^{*}$ & $0.35^{*}$ & - & $0.31^{*}$ & $0.15^{*}$ & $0.12^{*}$ \\
6. Delinquency WIII & -0.02 & $0.17^{*}$ & -0.04 & $0.21^{*}$ & $0.39^{*}$ & - & $0.14^{*}$ & $0.18^{*}$ \\
7. Arrests WIII & -0.01 & $0.18^{*}$ & $-0.08^{*}$ & $0.11^{*}$ & $0.24^{*}$ & $0.31^{*}$ & - & $0.21^{*}$ \\
8. Arrests WIV & 0.02 & $0.25^{*}$ & $-0.07^{*}$ & $0.08^{*}$ & $0.21^{*}$ & $0.20^{*}$ & $0.52^{*}$ & - \\
\hline
\end{tabular}

Correlations for the Black racial group are listed in the top diagonal, and the correlations for the White racial group are listed in the bottom diagonal

$* p<.05$ 
and a Satorra-Bentler Chi square difference test $\left(S-B \chi_{\text {diff }}^{2}\right)$ determined whether there was a significant group difference on the strength of the pathway (see Satorra \& Bentler, 2011). Mean and intercept differences of the variables in the model across race were finally examined employing the Satorra-Bentler Chi square difference test.

\section{Results}

The model examining the relationship between contextual factors, behaviors, and arrest outcomes was just identified. We tested for racial differences in each of the pathways, and tested a final model where any pathways in the model that were not significantly different between those who identify as Black and those who identify as White were held constant across the groups, and where they were significant we freely estimated them. The final model had good fit to the data: $\chi^{2}(11)=10.06, p>.05$, RMSEA $=.00(90 \%$ CI .00 to .01$)$, $\mathrm{SRMR}=.01, \mathrm{CFI}=1.00, \mathrm{TLI}=1.00$ (see Tables $3,4,5,6$ for all results).

Differences on the individual items making up the delinquency and drug use constructs as well as the overall constructs were identified. Chi square analyses identified several differences across race in engagement in delinquent behaviors. There were seven delinquent behaviors where race was not related to the frequency of the behavior: carrying a handgun at school or work $\left.\left(\chi^{2}(3)=6.99, p>.05\right)\right]$, using someone else's credit card $\left(\chi^{2}(3)=2.89, p>.05\right)$, or take part in a fight where a group of friends was against another group $\left(\chi^{2}(3)=3.16, p>.05\right)$, stealing something worth more than $\$ 50\left(\chi^{2}(3)=5.83, p>.05\right)$, deliberately
Table 4 Multiple-group longitudinal panel model results predicting Wave IV outcomes: Black participants $(n=2459)$ and White participants $(n=7403)$

\begin{tabular}{|c|c|c|}
\hline & \multicolumn{2}{|c|}{ Arrests young adulthood (WIV) } \\
\hline & Black & White \\
\hline Neighborhood disadvantage & $-5.76(1.53)^{* * * *}$ & $.46(.83)$ \\
\hline Exposure to violence & $.13(.14)$ & $.34(.06)^{* * *}$ \\
\hline Parent-child bond & $-.05(.05)$ & $-.05(.05)$ \\
\hline Alcohol use WIII & $-.01(.03)$ & $-.01(.03)$ \\
\hline Drug use WIII & $.09(.03)^{* *}$ & $.09(.03)^{* *}$ \\
\hline Delinquency WIII & $2.28(1.50)$ & $-.10(.57)$ \\
\hline Arrests WIII & $.38(.08) * * *$ & $.96(.17)^{* * *}$ \\
\hline Age & $-.10(.06)$ & $-.02(.02)$ \\
\hline Sex & $-1.10(.30)^{* * *}$ & $-.29(.06) * * *$ \\
\hline Income & $-.01(.00)$ & $-.00(.00)^{*}$ \\
\hline
\end{tabular}

Unstandardized results are presented in this table. Bolded responses are those where the strength of the association significantly differed between Black and White participants

$W$ wave

$* p<.05 ; * * p<.01 ; * * * p<.001$

damaging property $\left(\chi^{2}(3)=7.00, p>.05\right)$, selling marijuana or other drugs $\left(\chi^{2}(3)=6.66, p>.05\right)$, and stealing something worth less than $\$ 50\left(\chi^{2}(3)=11.60, p<.01\right)$. There were five behaviors of which the frequency of engagement was related to race, where those who identified as Black engaged the behavior more frequently than would be expected if race was not a significant factor: using a weapon to get something $\left(\chi^{2}(3)=47.19, p<.001\right)$, buying/selling/or holding stolen property $\left(\chi^{2}(3)=9.16, p<.05\right)$, deliberately writing a bad

Table 3 Multiple-group longitudinal panel model results predicting Wave III outcomes: Black participants $(n=2459)$ and White participants $(n=7403)$

\begin{tabular}{|c|c|c|c|c|c|c|c|c|}
\hline & \multicolumn{2}{|c|}{$\begin{array}{l}\text { Alcohol use emerging adult- } \\
\text { hood (WIII) }\end{array}$} & \multicolumn{2}{|c|}{$\begin{array}{l}\text { Drug use emerging adulthood } \\
\text { (WIII) }\end{array}$} & \multicolumn{2}{|c|}{$\begin{array}{l}\text { Delinquency emerging adult- } \\
\text { hood (WIII) }\end{array}$} & \multicolumn{2}{|c|}{$\begin{array}{l}\text { Arrests emerging adulthood } \\
\text { (WIII) }\end{array}$} \\
\hline & Black & White & Black & White & Black & White & Black & White \\
\hline $\begin{array}{l}\text { Neighborhood } \\
\text { disadvan- } \\
\text { tage }\end{array}$ & $-.73(.93)$ & $-6.39(.62)^{* * * *}$ & $=1.82(.48)^{* * * *}$ & $-.25(.75)$ & $-.16(.06)^{* *}$ & $-.16(.06)^{* *}$ & $-.86(.42)^{*}$ & $-.86(.42)^{*}$ \\
\hline $\begin{array}{l}\text { Exposure to } \\
\text { violence }\end{array}$ & $.07(.02)^{* *}$ & $.07(.02)^{* *}$ & $.07(.02)^{* * *}$ & $.26(.03)^{* * *}$ & $.02(.00)^{* * *}$ & $.02(.00)^{* * *}$ & $.18(.03)^{* * *}$ & $.18(.03)^{* * *}$ \\
\hline $\begin{array}{l}\text { Parent-child } \\
\text { bond }\end{array}$ & $-.08(.04)^{*}$ & $-.08(.04)^{*}$ & $-.12(.04)^{* *}$ & $-.36(.05)^{* * *}$ & $-.01(.00)^{* *}$ & $-.01(.00)^{* *}$ & $-.13(.03)^{* * *}$ & $-.13(.03) * * *$ \\
\hline Age & $.03(.03)$ & $.02(.02)$ & $-.03(.02)^{*}$ & $-.09(.02)^{* * *}$ & $-.01(.00)^{*}$ & $-.01(.00)^{* * *}$ & $.02(.02)$ & $-.01(.01)$ \\
\hline Sex & $-.51(.10)^{* * *}$ & $-.57(.05)^{* * *}$ & $-.25(.06)^{* * *}$ & $-.40(.06)^{* * *}$ & $-.07(.02)^{* * *}$ & $-.07(.01)^{* * *}$ & $-.56(.11)^{* * *}$ & $-.34(.04)^{* * *}$ \\
\hline Income & $.01(.00)^{*}$ & $.01(.00)^{* * *}$ & $.00(.00)$ & $.00(.00)^{* * *}$ & $.00(.00)$ & $.00(.00)^{* *}$ & $-.00(.00)^{* *}$ & $-.00(.00)^{*}$ \\
\hline
\end{tabular}

Unstandardized results are presented in this table. Bolded responses are those where the strength of the association significantly differed between Black and White participants

$W$ wave

$* p<.05 ; * * p<.01 ; * * * p<.001$ 
Table 5 Multiple-group longitudinal panel model standardized results predicting Wave III outcomes: Black participants $(n=2459)$ and White participants $(n=7403)$

\begin{tabular}{|c|c|c|c|c|c|c|c|c|}
\hline & \multicolumn{2}{|c|}{$\begin{array}{l}\text { Alcohol use emerging adult- } \\
\text { hood (WIII) }\end{array}$} & \multicolumn{2}{|c|}{$\begin{array}{l}\text { Drug use emerging adulthood } \\
\text { (WIII) }\end{array}$} & \multicolumn{2}{|c|}{$\begin{array}{l}\text { Delinquency emerging adult- } \\
\text { hood (WIII) }\end{array}$} & \multicolumn{2}{|c|}{$\begin{array}{l}\text { Arrests emerging adulthood } \\
\text { (WIII) }\end{array}$} \\
\hline & Black & White & Black & White & Black & White & Black & White \\
\hline $\begin{array}{l}\text { Neighborhood } \\
\text { disadvan- } \\
\text { tage }\end{array}$ & $\begin{array}{l}-.02(-.08 \\
\text { to } .03)\end{array}$ & $\begin{array}{c}-.14(-.17 \\
\text { to }-.12)^{*}\end{array}$ & $\begin{array}{c}-.10(-.15 \\
\text { to }-.05)^{*}\end{array}$ & $\begin{array}{l}-.01(-.03 \\
\text { to } .02)\end{array}$ & $\begin{array}{c}-.04(-.07 \\
\text { to }-.01)^{*}\end{array}$ & $\begin{array}{c}-.04(-.06 \\
\text { to }-.01)^{*}\end{array}$ & $\begin{array}{c}-.03(-.05 \\
\text { to }-.00)^{*}\end{array}$ & $\begin{array}{l}-.03(-.05 \text { to } \\
.00)^{*}\end{array}$ \\
\hline $\begin{array}{l}\text { Exposure to } \\
\text { violence }\end{array}$ & $\begin{array}{l}.05(.02 \text { to } \\
.08)^{*}\end{array}$ & $\begin{array}{l}.04(.02 \text { to } \\
.07)^{*}\end{array}$ & $\begin{array}{l}.08(.03 \text { to } \\
.14)^{*}\end{array}$ & $\begin{array}{l}.14(.10 \text { to } \\
.17)^{*}\end{array}$ & $\begin{array}{l}.14(.09 \text { to } \\
.18)^{*}\end{array}$ & $\begin{array}{l}.15(.10 \text { to } \\
.19)^{*}\end{array}$ & $\begin{array}{l}.12(.05 \text { to } \\
.19)^{*}\end{array}$ & $\begin{array}{l}.15(.11 \text { to } \\
.19)^{*}\end{array}$ \\
\hline $\begin{array}{l}\text { Parent-child } \\
\text { bond }\end{array}$ & $\begin{array}{l}-.03(-.06 \\
\text { to } .00)^{*}\end{array}$ & $\begin{array}{c}-.03(-.05 \\
\text { to } .00)^{*}\end{array}$ & $\begin{array}{c}-.08(-.13 \\
\text { to }-.02)^{*}\end{array}$ & $\begin{array}{c}-.11(-.14 \\
\text { to }-.08)^{*}\end{array}$ & $\begin{array}{r}-.04(-.07 \\
\text { to }-.02)^{*}\end{array}$ & $\begin{array}{r}-.05(-.08 \\
\text { to }-.02)^{*}\end{array}$ & $\begin{array}{r}-.05(-.07 \\
\text { to }-.02)^{*}\end{array}$ & $\begin{array}{l}-.06(-.09 \text { to } \\
-.03)^{*}\end{array}$ \\
\hline Age & $\begin{array}{l}.04(-.03 \text { to } \\
.10)\end{array}$ & $\begin{array}{l}.02(-.01 \text { to } \\
.05)\end{array}$ & $\begin{array}{c}-.06(-.12 \\
\text { to }-.01)^{*}\end{array}$ & $\begin{array}{c}-.08(-.11 \\
\text { to }-.05)^{*}\end{array}$ & $\begin{array}{c}-.09(-.15 \\
\text { to }-04)^{*}\end{array}$ & $\begin{array}{r}-.14(-.16 \\
\text { to }-.11)^{*}\end{array}$ & $\begin{array}{l}.02(-.03 \text { to } \\
.07)\end{array}$ & $\begin{array}{l}-.01(-.04 \text { to } \\
.01)\end{array}$ \\
\hline Sex & $\begin{array}{c}-.15(-.20 \\
\text { to }-.09)^{*}\end{array}$ & $\begin{array}{c}-.16(-.19 \\
\text { to }-.13)^{*}\end{array}$ & $\begin{array}{c}-.13(-.18 \\
\text { to }-.08)^{*}\end{array}$ & $\begin{array}{c}-.10(-.13 \\
\text { to }-.07)^{*}\end{array}$ & $\begin{array}{l}-.15(-20 \text { to } \\
-.10)^{*}\end{array}$ & $\begin{array}{c}-.20(-.22 \\
\text { to }-.17)^{*}\end{array}$ & $\begin{array}{c}-.16(-.19 \\
\text { to }-.12)^{*}\end{array}$ & $\begin{array}{l}-.13(-.16 \text { to } \\
-.11)^{*}\end{array}$ \\
\hline Income & $\begin{array}{c}.10(.03 \text { to } \\
.17)^{*}\end{array}$ & $\begin{array}{c}.16(.13 \text { to } \\
.18)^{*}\end{array}$ & $\begin{array}{l}.02(-.04 \text { to } \\
.08)\end{array}$ & $\begin{array}{c}.06(.03 \text { to } \\
.09)^{*}\end{array}$ & $\begin{array}{l}.00(-.05 \text { to } \\
.06)\end{array}$ & $\begin{array}{l}.04(.02 \text { to } \\
.07)^{*}\end{array}$ & $\begin{array}{r}-.06(-.09 \\
\text { to }-.12)^{*}\end{array}$ & $\begin{array}{c}-.03(-.04 \text { to } \\
-.01)^{*}\end{array}$ \\
\hline
\end{tabular}

Standardized results are presented in this table, and 95\% confidence intervals provided in parentheses

$W$ wave

$* p<.05$

Table 6 Multiple-group longitudinal panel model standardized results predicting Wave IV outcomes: Black participants $(n=2459)$ and White participants $(n=7403)$

\begin{tabular}{lll}
\hline & \multicolumn{2}{l}{ Arrests young adulthood (WIV) } \\
\cline { 2 - 3 } & Black & White \\
\hline Neighborhood disadvantage & $-.07(-.12 \text { to }-.02)^{*}$ & $.01(-.02$ to .03$)$ \\
Exposure to violence & $.04(-.05$ to .13$)$ & $.14(.09 \text { to } .18)^{*}$ \\
Parent-child bond & $-.01(-.02$ to .01$)$ & $-.01(-.04$ to .01$)$ \\
Alcohol use WIII & $-.00(-.02$ to .02$)$ & $-.01(-.04$ to .03$)$ \\
Drug use WIII & $.02(.00 \text { to } .04)^{*}$ & $.07(.03 \text { to } .11)^{*}$ \\
Delinquency WIII & $.11(.01 \text { to } .22)^{*}$ & $-.01(-.08$ to .07$)$ \\
Arrests WIII & $.16(.02 \text { to } .30)^{*}$ & $.47(.34 \text { to } .61)^{*}$ \\
Age & $-.05(-.09 \text { to }-.00)^{*}$ & $-.01(-.04$ to .02$)$ \\
Sex & $-.13(-.17 \text { to }-.08)^{*}$ & $-.06(-.08 \text { to }-.03)^{*}$ \\
Income & $-.03(-.06 \text { to }-.10)^{*}$ & $-.02(-.04 \text { to }-.00)^{*}$ \\
\hline
\end{tabular}

Standardized results are presented in this table, and 95\% confidence intervals provided in parentheses $W$ wave

$* p<.05 ; * * p<.01 ; * * * p<.001$ check $\left(\chi^{2}(3)=11.03, p<.05\right)$, going into a house or building to steal something $\left(\chi^{2}(3)=16.37, p<.01\right)$, or using a weapon in a fight $\left(\chi^{2}(3)=35.23, p<.001\right)$. Overall, there was no difference in the frequency of delinquent behaviors between those identifying as White and those as Black, Levene's test for equality of variances $F=3.06, p>.05, t(9805)=-1.12$, $p>.05$.

In examining drugs used between adolescence and emerging adulthood (i.e., Wave III), race was related to whether each drug, except steroids, had been used or not. Specifically, those who identified as White used each drug more often than would be expected if race was not related to drug use: steroids $\left(\chi^{2}(1)=3.25, p>.05\right)$, marijuana $\left(\chi^{2}(1)=172.22, p<.001\right)$, cocaine $\left(\chi^{2}(1)=227.06\right.$, $p<.001)$, methamphetamine $\left(\chi^{2}(1)=130.42, p<.001\right)$, other illegal drugs $\left(\chi^{2}(1)=388.90, p<.001\right)$, sedatives or downers $\left(\chi^{2}(1)=126.27, p<.001\right)$, tranquilizers $\left(\chi^{2}(1)=133.42, p<.001\right)$, stimulants or uppers $\left(\chi^{2}(1)=131.94, p<.05\right)$, pain killers $\left(\chi^{2}(1)=47.17\right.$, $p<.001)$. There was also a significant difference between those who identify as White and those who identify as Black in the number of drugs used, Levene's Test for Equality of Variances $F=766.41, p<.001$, $t(8260.51)=25.81, p<.001$. 


\section{Research Question 1: Examining the Direct Association Between Contextual Factors and Behavior and Arrest Outcomes}

Several contextual factors were similarly and significantly related to both behavior and outcome in emerging adulthood (i.e., Wave III) and young adulthood (i.e., Wave IV) for those who identify as Black and those who identify as White. Neighborhood disadvantage and parent-child bond were both related to less delinquency (neighborhood disadvantage $b=-.16, p<01$, parent-child bond $b=-.01$, $p<.01$ ) and arrests (neighborhood disadvantage $b=-.86$, $p<.05$, parent-child bond $b=-.13, p<.001$ ) in emerging adulthood, whereas exposure to violence was related to more delinquency $(b=.02, p<.001)$ and more arrests $(b=.18$, $p<.001)$ in emerging adulthood. Exposure to violence was also related to more alcohol use in emerging adulthood $(b=.07, p<.01)$, and parent child bond was related to less alcohol use in emerging adulthood $(b=-.08, p<.05)$.

\section{Research Question 2: Examining the Direct Association Between Behavior and Arrest Outcomes}

Drug use in emerging adulthood was related to a significant increase in the number of arrests $(b=.09, p<.01)$ in young adulthood, and was the only behavior that significantly predicted outcome in young adulthood similarly for those who identify as Black and those who identify as White.

\section{Research Question 3: Examining the Mean Differences in Contextual Factors}

There was a significant difference in the amount of neighborhood disadvantage across race $\left(S-B \chi_{\text {diff }}^{2}(1)=1246.86\right.$, $p<.05)$ with those who are Black having on average more neighborhood disadvantage $(M=.21)$ than those who identify as White $(M=.15)$. There was a significant difference in the amount of exposure to violence across race $(S-B$ $\left.\chi_{\text {diff }}^{2}(1)=144.38, p<.05\right)$ with those who identify Black $(M=.99)$ having more exposure to violence than those who identify as White $(M=.61)$. There was a significant difference in parent-child bond across race $\left(S-B \chi_{\text {diff }}^{2}(1)=5.37\right.$, $p<.05)$ for those who identify as White $(M=4.34)$ and those who identify as Black $(M=4.40)$.

\section{Research Question 3: Examining the Mean Differences in Behavior}

There was a significant difference in the amount of alcohol use across race $\left(S-B \chi_{\text {diff }}^{2}(1)=8.88, p<.05\right)$ for those who identify as White $(M=3.33)$ and those who identify Black $(M=1.43)$ which shows that those who identify as White are more likely to engage in alcohol use. Similarly, for drug use there is a significant difference across race ( $S-B$ $\left.\chi_{\text {diff }}^{2}(1)=19.94, p<.05\right)$ for those who identify as White $(M=4.34)$ and those who identify as Black $(M=2.10)$.

\section{Research Question 3: Examining the Mean Differences in Arrest Outcomes}

After holding the effect of contextual factors in adolescence, behaviors in emerging adulthood, and arrests in emerging adulthood constant, a significant difference in the number of arrests across race $\left(S-B \chi_{\text {diff }}^{2}(1)=4.24, p<.05\right)$ emerges in young adulthood. Compared to those who identify as White $(M=.62)$, those who identify as Black $(M=4.30)$ were arrested almost seven times more often.

\section{Research Question 4: Examining the Differences across Race on the Strength of Relation between Contextual Factors, Behavior, and Arrest Outcomes}

Several contextual factors were more strongly related to behavioral outcomes in emerging adulthood for one race as compared to the other. Neighborhood disadvantage was only negatively related to alcohol use for those who identify as being White $(b=-6.39, p<.001$; Black $b=-.73$, $p>.05$ ), and only negatively related to drug use for those who identify as being Black $(b=-1.82, p<.001$; White $b=-.25, p>.05$ ). Exposure to violence and parent-child bond were more strongly related to drug use for those who identify as White (exposure to violence $b=.26, p<.001$; parent-child bond $b=-.36, p<.001)$ than those who identify as Black (exposure to violence $b=.07, p<.01$; parent-child bond $b=-.12, p<.01)$. Some contextual factors emerged as significant predictors of young adult arrests for only one race, but not the other. Neighborhood disadvantage only related to number of arrests in young adulthood for those who identify as Black (Black $b=-5.76, p<.001$; White $b=.46, p>.05$ ), whereas exposure to violence was only a significant predictor of young adulthood arrests for those who identify as White (White $b=.34, p<.001$; Black $b=.13, p>.05$ ). Arrests in emerging adulthood were predictive of later arrests more strongly for those who identify as White $(b=.96, p<.001)$ compared to those who identify as Black $(b=.38, p<.001)$. A follow-up repeated-measures factorial ANOVA identified that this difference in strength of the association between arrests in emerging and young adulthood was due to the fact that Black adults experienced a much larger increase in number of arrests. There was a significant effect of time $F(1,9845)=114.94, p<.001$, race $F(1,9845)=7.32, p<.01$, and there was a significant interaction between race and time $F(1,9845)=8.35, p<.01$. 


\section{Discussion}

Racial disparities in arrest are an ongoing issue that should be alarming to the public. Individuals who identify as Black are twice as likely to be arrested as individuals who identify as White (Barnes et al., 2014). Moving beyond examining likelihood for arrest, our study examined differences in frequency of arrest, and after controlling for factors implicating three different theories, we estimate this rate to be seven times greater for Black young adults. This concerning and harmful disparity causes greater systemic issues for the communities experiencing the effects of high arrest rates (Pratt et al., 2016). Those who are affected by this disparity including families, communities, jobs, and the education system, are being greatly impacted (Pratt et al., 2016). These racial disparities and the findings from this research have implications for future clinical and advocacy practices aimed to help racial disparities in arrests decline. In this paper, we simultaneously tested the Social Disorganization Theory, Differential Involvement Hypothesis, and Differential Selection and Processing Hypothesis. The main factors included within the model to test each of these theories included contextual factors (i.e., neighborhood disadvantage, exposure to violence, and parent-child bond), behaviors (i.e., alcohol use, drug use, and delinquency), and arrest outcomes (i.e., number of arrests). By discovering factors that impact the disparity, individuals advocating for youth including clinicians, teachers, and society at large, can begin to plan how to prevent overrepresentation of this population in the criminal justice system, as well as, the families and communities that are impacted, as each theory has different implications for clinical practice.

\section{Social Disorganization Theory}

Social Disorganization Theory believes that socioeconomic disadvantage and residential instability hurts social bonds in the community that can impact the ability to have social control over a community (Beyer, Wallis, \& Hamberger, 2013; Gase et al., 2016). Socioeconomic disadvantage impacts social bonds, leading to increases in violent behavior, and an increased police presence. All of which account for an increase in arrests for members of the community. Racial differences in arrest are accounted for by the differences in socioeconomic disadvantage generally experienced by different groups (Beyer et al., 2013; Gase et al., 2016). We only found partial support for the Social Disorganization Theory. Particularly, neighborhood disadvantage and exposure to violence were both higher among the Black population as compared to the White population; however, despite the greater adversity, parent-child bond was higher on average in the Black group. Although Social Disorganization Theory suggests that neighborhood disadvantage should increase risk and should account for differences between groups in delinquent behavior and arrest rates, we did not find this to be the case. In fact, neighborhood disadvantage levels were related to less delinquent behaviors and less arrests in emerging adulthood, and less alcohol use and delinquency in young adulthood. Rather than neighborhood disadvantage, exposure to violence was a predictor of more alcohol use in young adulthood. Therefore, it seems as though violence is a stronger predictor of negative outcomes than neighborhood disadvantage according to our findings. The strength of the effect of exposure to violence also tended to be stronger than neighborhood disadvantage and parent-child bond, particularly when predicting later delinquency and arrest. If Social Disorganization Theory explained the disparities in arrest across Black and White racial groups, then we would not see a difference in the rate of arrest after controlling for contextual factors, nor would we see a difference in how the contextual factors predict arrest or behavioral outcomes. Increase in police presence and then likelihood for arrest would both coincide with disadvantage and violence rates; contextual factors would fully explain the disparities. However, in our study, there continued to be an observed difference in young adult arrest outcomes, as well as differences in the strength of contextual factors as predictors across Black and White participants.

\section{Differential Involvement Hypothesis and Differential Selection and Processing Hypothesis}

The Differential Involvement and Differential Selection and Processing Hypotheses, are antithesis to one another in many ways. The Differential Involvement Hypothesis suggests that Black individuals are engaging in more delinquent behavior, therefore causing them to be arrested more than White individuals (Gase et al., 2016). Whereas, the Differential Selection and Processing Hypothesis believes that there are not differential rates of delinquent behavior between Whites and Blacks, but instead differential arrest rates are accounted for by unconscious racial stereotyping by police (Gase et al., 2016). The Differential Involvement Hypothesis expects differences in behavior across the racial groups, and expects a higher rate of arrest, but not after controlling for behavioral differences, and expects no difference in how contextual factors or earlier behaviors are related to outcome. The Differential Selection and Processing Hypothesis expects the opposite findings, no difference in behavior, but differences in arrest, and even a differential relation between contextual factors, behavior, and outcome. Our results found that there 
were in fact differences in the behaviors across racial groups, but counter to what the Differential Involvement Hypothesis would suggest based on arrest disparities. We found that after controlling for contextual factors the Black group engaged in less substance use in emerging adulthood, both alcohol and drug, but similar delinquency; yet were also the group that had a rate of arrest in young adulthood almost seven times greater than the White group and experienced a greater increase in the number of arrests between emerging and young adulthood.

For the Black group, neighborhood disadvantage was related to less arrests in young adulthood, and earlier arrests were less strongly related to later arrests as compared to the White group. The Black group still had an average arrest rate that was seven times greater than the White group. This disparity was found despite having on average less alcohol use, less drug use, and similar rates of delinquency and arrest in emerging adulthood. It was also found despite neighborhood disadvantage being related to less likelihood for arrest and earlier arrest being less strongly related to later arrests, and also despite controlling for these factors and differences including disproportionate neighborhood disadvantage and exposure to violence and greater parent-child bond. Behavior did not account for the differences in arrest, contextual factors did not account for the differences in arrest, findings of which seem to support the Differential Selection and Processing Hypothesis can account for the differences in arrest. If it is not behavior and it is not context, then perhaps unconscious racial bias and stereotyping by the police and criminal justice system can account for the differences. Interestingly, for the Black group, having more neighborhood disadvantage was related to having less exposure to violence, where for the White group more neighborhood disadvantage was related to having more exposure to violence. Could this also point to the Differential Selection and Processing Hypothesis? Perhaps the more disadvantaged Black neighborhoods have a greater police presence compared to disadvantaged White neighborhoods, leading to less violence occurring, but also a greater opportunity for arrest for similar behavior as White peers.

\section{Implications for Practice}

It is imperative for clinicians to be aware of disparities when working with families of different races and cultures, as well as being aware of differences in how risk or protective factors affect outcomes so that treatment can be adjusted accordingly. This study found that some factors that predicted problematic behaviors and arrest rates in the future were stronger predictors for one race as compared to the other. For example, although parent-child bond was related to reduced frequency of alcohol use, less drugs used, less delinquency, and less arrests in emerging adulthood, it was a much stronger predictor of less drugs used for the White sample. Further, parent-child bond was only significantly related to young adulthood outcomes for the White sample. All of this was found despite the fact that Black adolescents reported on average greater parent-child bond than did White adolescents. Thus, while focusing on parent-child bond with a White family may be helpful in reducing the likelihood for some problematic behavior later on, a Black family may need treatment to focus on different factors to negate these negative outcomes. Mental health clinicians are held to the standard of cultural competence (Arrendondo, 1999). Each individual exists in many different contexts of the world that work together to influence their well-being (Arrendondo, 1999). Therefore, neglecting the different contexts of the individual can be damaging. For example, responsibility for patterns and problems brought into the therapy room may be misappropriated if there is no discussion of the context and community that the family and child are living in, particularly the historical, racial, and social context (McAdams-Mahmoud, 2008). We fear the internalization of blame and shame for minority communities if we do not also implicate societal expectancies as part of their experience. We believe that it is incredibly crucial, particularly when working with racial/ethnic minorities, for a clinician to spend ample time assessing not only for behavioral patterns of the client and their family, but also assessing the context of the client's broader community. This should include the resources available within the community, the threat of violence within one's community, the policing practices in that area, and the relationship between the community and the police. The clinician should place whatever challenges the client is facing within the broader societal system in order to contextualize their experience and properly prepare the client for challenges they may face. Consideration of the social reality can change the focus of treatment and can aid families in working together to face this common external problem rather than blaming one another. These disparities also support that when working with Black individuals in therapy who are experiencing oppression, beyond what can be addressed in session, clinicians are called to access resources and advocate for them in additional contexts.

We want to reiterate here some of the ways that clinicians can impact their clients outside of the therapy room, which may result in greater systemic change for some communities than therapy alone can provide. As clinicians we are uniquely qualified to address issues outside of the therapy room, such as racism, that can be emotionally charged and sensitive to the individuals we work with and desire to help. Hardy (2008) gives three suggestions on how to be a clinician and advocate for your clients. The first suggestion is that we must be informed and acknowledge the disparities and stand up to break the silence that this topic holds. This means we need to be in continual communication about the 
disparities people face and how we can become advocates for change. This study gives the context of information for clinicians to utilize when relying on the facts to have these conversations. The second is, when we are in continual communication, we must do so in a way that will be effective to those listening. We must account for all differences and have dialogue in a way that will heal the bridge between opposing sides. While doing so we must understand our position of privilege and power as a clinician, and how these factors can affect our position in advocating for change. This study highlights possible police bias and larger systemic issues for minority populations, yet seeks to educate and inform in a helpful, not demeaning way. We recognize that society has impacted our privilege and hope that education and communication can relinquish the power that we hold. The third being, within these conversations, we must "promote critical racial introspection" by facilitating these conversations in a meaningful way that will shed light to this topic. For clinicians the process of educating others, who exist outside of the context of the therapy room and advocating for clients, can begin with the conversation of privilege and how it prevents minorities from having equal opportunity (Hardy, 2008). This paper highlights the need for help beyond creating healthy family bonds. We are proposing that clinicians use their unique skills beyond the their typical scope and instead help create larger systemic change.

\section{Strengths and Limitations}

Studies examining racial disparities in arrest have done so using large nationally representative populations (Donaldson, Handren, \& Crano, 2016; Gase et al., 2016; Slutske et al., 2016), and have used longitudinal, rather than retrospective, data to predict future arrest (Donaldson et al., 2016; Gase et al., 2016). However, it has been common practice when examining arrest disparities, to examine whether or not arrest has occurred rather than frequency of arrest differences. This study expanded the literature by examining a lifetime number of arrests, and comparing differences in predictors between Black and White racial groups. Dichotomizing arrest record minimizes the observed variability between Black and White racial groups, and could minimize our ability to account for the full range of differences experienced by these populations. Being a large dataset, we were capable of detecting even fairly small effect sizes (see Tables 5, 6), and would like to note that although statistically significant, some of the effects were rather small. We believe that given the complexity of the assessment of some of these constructs, the amount of time that passed between assessments (over 14 years between Wave I and Wave IV), and the large variability of participants, that even the small findings are important and warrant further examination. This study was able to simultaneously test factors from three theories that attempt to explain arrest disparities, using data from a large longitudinal study with a nationally representative population. Although the contextual data examined was compiled through census information about neighborhoods in which participants lived, the report of violence witnessed, amount of substance use, and number of arrests were all self-report items, of which social desirability response bias could lead to underreported representations of the objective truth (van de Mortel, 2008), or in which inaccuracies may present themselves. Finally, this study tested and controlled for factors involved in both the Social Disorganization Theory and the Differential Involvement Hypothesis leaving any remaining observed differences as implicating the Differential Selection and Processing Hypothesis. However, bias in policing or the justice system was not directly assessed within the context of this study. With neither differences in contextual factors nor differences in behaviors accounting for the observed arrest disparities between Black and White young adults, a critical lens examining additional factors that can account for these differences is crucial. Future research should continue to directly examine this particular factor when considering disparities in arrest across racial/ethnic groups.

\section{Conclusion}

The mass incarceration of Black individuals in this country is a major problem that has significant impacts on the Black community (Hamil-Luker, 2008). Researchers have attempted to explain this disparity by examining differences in exposure to risk factors, differences in behaviors, and differences in unconscious bias and police targeting between White and Black individuals. Black adolescents in this study were situated in more disadvantaged neighborhoods with greater violence occurring and yet maintained stronger parent-child relationships, and tended to have no greater problematic behavior rates, they even drank less frequently and used less drugs in emerging adulthood than their White counterparts. Despite all this, and after controlling for all these factors, Black participants were still arrested at a rate that was seven times more frequent than White participants. Neither contextual nor behavioral differences account for the arrest disparity between those who are Black and those who are White.

Our study sheds light on racial disparities that are not accounted for by contextual or behavioral factors, implying there is a need for self-reflection in order to begin to understand that we each hold bias that can perpetuate this cycle of oppression. Our hope is that this information will be used as 
an intervention in this process of educating others and advocating for those who are marginalized. This intervention can begin with the conversation of privilege and how it prevents minorities from having equal opportunity (Hardy, 2008). As we continue to advocate and educate and treat families, we can hopefully create change that can help decrease this racial disparity in arrests. We are proposing that clinicians and individuals who hold power, use their privilege to help educate police officers, school educators, and communities at large on how to best serve this marginalized population. It is time that research turns to examining more critically how unconscious bias and stereotyping, especially by the justice system, are impacting lives of Black Americans.

Acknowledgements This research uses data from Add Health, a program project directed by Kathleen Mullan Harris and designed by J. Richard Udry, Peter S. Bearman, and Kathleen Mullan Harris at the University of North Carolina at Chapel Hill, and funded by grant P01-HD31921 from the Eunice Kennedy Shriver National Institute of Child Health and Human Development, with cooperative funding from 23 other federal agencies and foundations. Special acknowledgment is due Ronald R. Rindfuss and Barbara Entwisle for assistance in the original design. Information on how to obtain the Add Health data files is available on the Add Health website (http://www.cpc.unc.edu/ addhealth). No direct support was received from grant P01-HD31921 for this analysis.

Funding The authors declare there was no funding involved in this research project.

\section{Compliance with Ethical Standards}

Conflict of interest The authors declare no conflicts of interest.

Ethical Approval All procedures performed in studies involving human participants were in accordance with ethical standards of the institutional review board.

Informed Consent The ADD Health researchers obtained informed consent from all individual participants included in the study.

\section{References}

Arredondo, P. (1999). Multicultural counseling competencies as tools to address oppression and racism. Journal of Counseling \& Development, 77, 102-108. https://doi.org/10.1002/j.1556-6676.1999.tb024 27. $\mathrm{x}$.

Barnes, J. C., Jorgensen, C., Beaver, K. M., Boutwell, B. B., \& Wright, J. P. (2014). Arrest prevalence in a national sample of adults: The role of sex and race/ethnicity. American Journal of Criminal Justice, 40, 457-465.

Bechtold, J., Monahan, K., Wakefield, S., \& Cauffman, E. (2015). The role of race in probation monitoring and responses to probation violations among juvenile offenders in two jurisdictions. Psychology, Public Policy, and Law, 21, 323-337.

Beyer, K., Wallis, A. B., \& Hamberger, L. K. (2013). Neighborhood environment and intimate partner violence. Trauma, Violence, \& Abuse, 16, 16-47. https://doi.org/10.1177/1524838013515758.
Carson, E. A., \& Golinelli, D. (2013). Prisoners in 2012-Advance counts. Washington, DC: U.S. Department of Justice.

Chantala, K. (2006). Guidelines for analyzing Add Health data. Chapel Hill, NC: University of North Carolina at Chapel Hill. Carolina Population Center.

Crosnoe, R., \& Elder, G. H. (2004). Family dynamics, supportive relationships, and educational resilience during adolescence. Journal of Family Issues, 25, 571-602.

Donaldson, C. D., Handren, L. M., \& Crano, W. D. (2016). The enduring impact of parents' monitoring, warmth, expectancies, and alcohol use on their children's future binge drinking and arrests: A longitudinal analysis. Prevention Science, 17, 606-614. https://doi. org/10.1007/s11121-016-0656-1.

Gase, L. N., Glenn, B. A., Gomez, L. M., Kuo, T., Inkelas, M., \& Ponce, N. A. (2016). Understanding racial and ethnic disparities in arrest: The role of individual, home, school, and community characteristics. Race and Social Problems, 8, 296-312.

Graham, S., \& Lowery, B. S. (2004). Priming unconscious racial stereotypes about adolescent offenders. Law and Human Behavior, 28, 483-504.

Hamil-Luker, J. (2008). Delinquency, incarceration and health in midlife: Racial/ethnic disparities among Black, Hispanic and White men. Paper presented at the American Sociological Association Conference.

Hardy, K. V. (2008). Race, reality and relationships-implications for the re-visioning of family therapy. In M. McGoldrick \& K. V. Hardy (Eds.), Re-visioning of family therapy (2nd ed., pp. 76-84). New York: The Guilford Press.

Harris, K. M., Halpern, C. T., Whitsel, E., Hussey, J., Tabor, J., Entzel, P., \& Udry, J. R. (2009). The National Longitudinal Study of Adolescent Health: Research Design [WWW document]. http://www.cpc.unc. edu/projects/addhealth/design.

Kamalu, N. C., Coulson-Clark, M., \& Kamalu, N. M. (2010). Racial disparities in sentencing: Implications for the criminal justice system and the African American Community. African Journal of Criminology \& Justice Studies, 4, 1-8.

Kubrin, C. E., \& Stewart, E. A. (2006). Predicting who reoffends: The neglected role of neighborhood context in recidivism studies. Criminology, 44, 165-197.

McAdams-Mahmoud, V. (2008). Understanding families in the context of cultural adaptations to oppression. In M. McGoldrick \& K. V. Hardy (Eds.), Re-visioning family therapy: Race, culture, and gender in clinical practice (pp. 85-93). New York: The Guilford Press.

Mitchell, O., \& Caudy, M. S. (2013). Examining racial disparities in drug arrests. Justice Quarterly, 32, 288-313.

Muthén, L. K., \& Muthén, B. O. (1998-2012). Mplus user's guide (8th ed.). Los Angeles, CA: Muthén \& Muthén.

Piquero, A. R. (2008). Disproportionate minority contact. The Future of Children, 18, 59-79.

Pratt, T. C., Barnes, J. C., Cullen, F. T., \& Turanovic, J. J. (2016). "I suck at everything": Crime, arrest, and the generality of failure. Deviant Behavior, 37, 837-851. https://doi.org/10.1080/01639 625.2016.1147809.

Puzzanchera, C., \& Hockenberry, S. (2015). National disproportionate minority contact databook. Pittsburgh, PA: National Center for Juvenile Justice for the Office of Juvenile Justice and Delinquency Prevention.

Sampson, R., \& Groves, W. (1989). Community structure and crime: Testing social-disorganization theory. American Journal of Sociology, 94, 774-802.

Satorra, A., \& Bentler, P. (2011). A scaled difference Chi square test for moment structure analysis. Psychometrika, 66, 507-514.

Slutske, W. S., Deutsch, A. R., \& Piasecki, T. M. (2016). Neighborhood contextual factors, alcohol use, and alcohol problems in the United States: Evidence from a nationally representative study of young 
adults. Alcoholism, Clinical and Experimental Research, 40, 10101019. https://doi.org/10.1111/acer.13033.

Spohn, C. (2000). Thirty years of sentencing reform: The quest for a racially neutral sentencing process. Criminal Justice, 3, 427-501.

van de Mortel, T. F. (2008). Faking it: Social desirability response bias in self-report research. Australian Journal of Advanced Nursing, $25,40-48$.
Publisher's Note Springer Nature remains neutral with regard to jurisdictional claims in published maps and institutional affiliations. 